ORIGINAL ARTICLE

\title{
Augmented expression of secondary lymphoid tissue chemokine and EBII ligand chemokine in Crohn's disease
}

\author{
D Kawashima, N Oshitani, Y Jinno, K Watanabe, S Nakamura, K Higuchi, T Arakawa
}

J Clin Pathol 2005;58:1057-1063. doi: 10.1136/jcp.2004.024828

See end of article for authors' affiliations

Correspondence to:

Dr N Oshitani, Department

of Gastroenterology,

Osaka City University

Graduate School of

Medicine 1-4-3, Asahi-

machi, Abeno-ku, Osaka

545-8585, Japan; nobu@

med.osaka-cu.ac.jp

Accepted for publication

3 February 2005
Background: A dominant T helper type 1 (Th1) immune response is thought to be involved in Crohn's disease (CD). SLC/CCL21 and ELC/CCL19, chemokines that regulate T cell homing and promote recirculating $T$ and dendritic cell (DC) interactions, help control antigen specific $T$ cell responses.

Aims: To investigate the Th1 response and SLC and ELC in CD pathogenesis.

Methods: Surgically resected intestine and mesenteric lymph nodes (MLNs) from controls and patients with CD and ulcerative colitis (UC) were investigated. CD3, CD83, HECA452, VEGFR3, SLC, ELC, and CCR7 expression was studied immunohistochemically. CCR7 mRNA was quantified using real time RT-PCR.

Results: ELC was almost undetectable in intestinal samples. SLC was found sporadically in lymphoid follicles, lymphoid aggregate venules, and lymphatic vessels. In MLNs, SLC was highly expressed in high endothelial venules (HEVs), lymphatic vessels, and stromal DCs, predominantly in T cell areas. ELC was highly expressed in mature DCs. There were significantly more SLC positive HEVs and ELC positive mature DCs, important components of T cell areas, in CD. SLC, ELC, and CCR7 mRNA was significantly higher in CD MLNs compared with UC. CD MLNs had increased expression of SLC and ELC, mainly in HEVs, mature DCs, and lymphatic vessels, inducing T cell hyperplasia. CCR7 mRNA was increased in T cell areas.

Conclusion: The dominant Th1 immune response is facilitated by interaction of SLC positive HEVs/ lymphatic vessels, ELC positive mature DCs, and CCR7 positive T cells in hyperplastic T cell areas. In CD, memory $T$ cells and mature DCs may home to MLN.
C rohn's disease is an intractable intestinal disease of unknown aetiology that can involve the entire digestive tract from mouth to anus, but particularly the ileum and large intestine. Longitudinal ulcers and a cobblestone appearance are characteristic findings of Crohn's disease, and a pathognomonic feature of the disease is a histological finding of non-caseating epithelioid cell granuloma. It has been suggested that immunological dysregulation is involved in the pathogenesis of Crohn's disease, ${ }^{12}$ and recent studies revealed that $\mathrm{T}$ helper type $\mathrm{l}$ (Thl) skewing may affect the immune response of patients with Crohn's disease. ${ }^{3-9}$ In addition, macrophage dysfunction may play a role in the aetiology of Crohn's disease because macrophages in patients with this disease phagocytose and process ingested antigens in the intestine and lymph nodes, resulting in granuloma formation. ${ }^{3}$ Antigen presenting cells such as macrophages and dendritic cells are key cells that influence the Th1 or Th2 differentiation of $\mathrm{T}$ cells. We have reported the expression of costimulatory molecules on macrophage lineages in Crohn's disease intestine that function as antigen presenting cells to elicit Thl dominant $\mathrm{T}$ cell immunity. ${ }^{5}$

\section{"Recent studies revealed that T helper type 1 skewing may affect the immune response of patients with Crohn's disease"}

Chemokines, categorised as CC and CXC subgroups according to their molecular structure, are not only chemoattractant to various white blood cells but are involved in the Th1 and Th2 differentiation of $\mathrm{T}$ cells. ${ }^{11-13}$ Secondary lymphoid tissue chemokine (SLC), known as CCL21, and EBIl ligand chemokine (ELC), known as CCL19, are CC chemokines derived from the pl2 gene on chromosome 9, which recognise chemokine receptor 7 (CCR7) as their cellular receptor. SLC was established from the plt/plt mouse, which has immature peripheral lymph organs. ${ }^{14}$ SLC is found in the high endothelial venules (HEVs) of lymphoid tissue and lymph vessels, which are involved in the homing of $\mathrm{T}$ cells and dendritic cells. ${ }^{15}$ ELC was first identified as a functional ligand of CCR7. ${ }^{16}$ ELC is found in mature dendritic cells and plays an important role in T cell interactions. ${ }^{17}{ }^{18}$

We investigated intestinal and mesenteric lymph node localisation and expression of SLC and ELC in controls, in patients with ulcerative colitis (UC), and in patients with Crohn's disease. We also measured the expression of SLC, ELC, and CCR7 mRNA to clarify the role of these chemokines in the pathogenesis of Crohn's disease.

\section{MATERIALS AND METHODS \\ Subjects}

Surgical specimens taken from the lower intestine and mesenteric lymph nodes were obtained from 22 patients with Crohn's disease (seven ileitis, 13 ileocolitis, and two colitis), 18 patients with UC ( 16 total colitis type and two left sided colitis type), and 10 controls (table 1). An approximately $5 \times 5 \times 2 \mathrm{~mm}$ segment was cut from the intestine, and whole mesenteric lymph nodes were fixed in periodate/ lysine $/ 2 \%$ paraformaldehyde at $4{ }^{\circ} \mathrm{C}$ for six hours, then continuously incubated in a $10 \%, 15 \%$, and $20 \%$ sucrose gradient in phosphate buffered saline (PBS) at $4{ }^{\circ} \mathrm{C}$ for six hours each. Specimens were embedded in OCT compound (Miles Sankyo, Tokyo, Japan) in dry ice/acetone, and stored at $-80^{\circ} \mathrm{C}$ until use. Informed consent was obtained from all

\footnotetext{
Abbreviations: ELC, EBI1 ligand chemokine; GALT, gut associated lymphoid tissue; HEV, high endothelial venule; IL, interleukin; PBS, phosphate buffered saline; PBS-T, phosphate buffered saline Tween; $\mathrm{PCR}$, polymerase chain reaction; RT, reverse transcription; SLC, secondary lymphoid tissue chemokine; Th1/2, T helper type 1/2
} 
Table 1 Clinical background of the patients

\begin{tabular}{|c|c|c|c|}
\hline & Ulcerative colitis & Crohn's disease & Controls \\
\hline No. of patients & 18 & 22 & 10 \\
\hline Male/female & $10 / 8$ & $17 / 5$ & $4 / 6$ \\
\hline Mean (range) age (years) & $42(17-71)$ & $32(22-53)$ & $61(52-74)$ \\
\hline Mean (range) duration of disease (years) & $4(0-15)$ & $3(2-8)$ & \\
\hline \multicolumn{4}{|l|}{ Location of Crohn's disease } \\
\hline Ileitis & & 7 & \\
\hline Colitis & & 2 & \\
\hline Ileocolitis & & 13 & \\
\hline \multicolumn{4}{|l|}{ Behaviour of Crohn's disease } \\
\hline Non-stricturing, non-penetrating type & & 2 & \\
\hline Stricturing type & & 14 & \\
\hline Penetrating type & & 6 & \\
\hline \multicolumn{4}{|l|}{ Extent of ulcerative colitis } \\
\hline Left sided colitis & 2 & & \\
\hline Total colitis & 16 & & \\
\hline \multicolumn{4}{|l|}{ Medical treatment } \\
\hline Sulfasalazine or mesalazine & 18 & 12 & \\
\hline Corticosteroids & 18 & 7 & \\
\hline Azathioprine or 6-mercaptopurine & 0 & 4 & \\
\hline
\end{tabular}

patients and our study was approved by the university's ethics committee.

\section{Immunohistochemistry}

Cryostat sections ( $5 \mu \mathrm{m}$ thick) were pretreated with $2 \%$ goat serum to inhibit non-specific protein binding, and then endogenous peroxidase activity was inactivated by treatment with PBS with $0.1 \%$ sodium azide and $0.3 \%$ hydrogen peroxide for 10 minutes. After washing, sections were first reacted with a panel of primary antibodies (anti-CD3, antiCD83, anti-HECA452, anti-VEGFR3, anti-SLC, anti-ELC, and anti-CCR7; table 2) at $4^{\circ} \mathrm{C}$ overnight.

After washing three times in PBS, sections were reacted with goat antimouse immunoglobulin conjugated to peroxidase labelled dextran polymer (Dako EnVision $+{ }^{\mathrm{TM}}$,

\begin{tabular}{|c|c|c|c|}
\hline Antibody to & Source & Animal & Dilution \\
\hline CD3 & Immunotech, Marseille, France & Mouse & $1 / 100$ \\
\hline CD83 & Immunotech & Mouse & $1 / 100$ \\
\hline HECA452 & $\begin{array}{l}\text { BD Pharmingen, San Diego, } \\
\text { California, USA }\end{array}$ & Rat & $1 / 200$ \\
\hline VEGFR3 & $\begin{array}{l}\text { Dr A Saaristo, University of } \\
\text { Helsinki, Finland }\end{array}$ & Mouse & $1 / 1000$ \\
\hline SLC & R\&D Systems, Abington, UK & Goat & $1 / 400$ \\
\hline ELC & $\begin{array}{l}\text { Dako, Carpinteria, California, } \\
\text { USA }\end{array}$ & Goat & $1 / 200$ \\
\hline CCR7 & MBL Co Ltd, Nagoya Japan & Mouse & $1 / 400$ \\
\hline
\end{tabular}

peroxidase, mouse, ready-to-use; Dako, Carpinteria, California, USA). The peroxidase-substrate reaction was developed with $0.03 \%$ 3',3-diaminobenzidine tetrahydrochloride containing $0.006 \%$ hydrogen peroxide and $0.065 \%$ sodium azide in Tris buffered saline, and nuclear counterstaining was performed with methyl green. The specificity of the antibodies was confirmed by using the same subclass of non-immunised immunoglobulins conjugated with peroxidase for monoclonal antibodies, and by absorption test for polyclonal antibodies.

SLC positive HEVs and ELC positive mature dendritic cells were counted under $\times 400$ magnification over five microscopic fields using an optical grid in the mesenteric lymph nodes ( 12 lymph nodes from patients with Crohn's disease and 10 lymph nodes from patients with UC) and expressed as venules or cells $/ \mathrm{mm}^{2}$.

\section{Immunofluorescent double staining}

Immunofluorescent double staining was performed to detect CD83 and ELC. Tissue sections were prepared as described earlier. Sections were reacted with anti-CD83 monoclonal antibody at a $1 / 100$ dilution at $4^{\circ} \mathrm{C}$ overnight, washed with PBS containing $0.05 \%$ Tween-20 (PBS-T), and further reacted with rhodamine conjugated goat antimouse IgG antibody (CHEMICON International, Temecula, California, USA) at a $1 / 50$ dilution at ambient temperature for 60 minutes. Sections were washed with PBS-T, and reacted with goat anti-ELC antibody (DAKO A/S, Glostrup, Denmark) at a $\mathrm{l} /$ 200 dilution, at $4^{\circ} \mathrm{C}$ overnight. After washing with PBS-T, sections were reacted with fluorescein conjugated goat

Table 3 Primers and probes used in real time quantitative polymerase chain reaction

\begin{tabular}{|c|c|c|}
\hline Primer/probe & & Sequence \\
\hline \multicolumn{3}{|l|}{ SLC } \\
\hline & Sense primer & 5'-ACCAAGCTTAGGCTGCTCCAT-3' \\
\hline & Antisense primer & 5'-TGCACATAGCTCTGCCTGAGAG-3' \\
\hline & Probe (FAM labelled) & 5'-AGCTATCCTGTTCTTGCCCCGCAA-3' \\
\hline \multicolumn{3}{|r|}{ 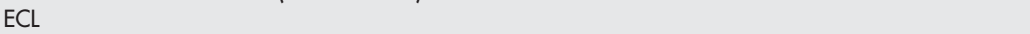 } \\
\hline & Sense primer & 5'-AATGATGCTGAAGACTGCTGC-3' \\
\hline & Antisense primer & 5'-TGGAAGTTCCTCACGATGTACC-3' \\
\hline & Probe (FAM labelled) & 5'-TGTCTGTGACCCAGAAACCCATCCCT-3' \\
\hline \multicolumn{3}{|l|}{ CCR7 } \\
\hline & Sense primer & 5'-AAGAAGGACGTGCGGAACTT-3' \\
\hline & Antisense primer & 5'-GGCCCACGAAACAAATGA-3' \\
\hline & Probe (FAM labelled) & 5'-AAAGCCTGGTTCCTCCCTATCATGTACTCC-3' \\
\hline
\end{tabular}



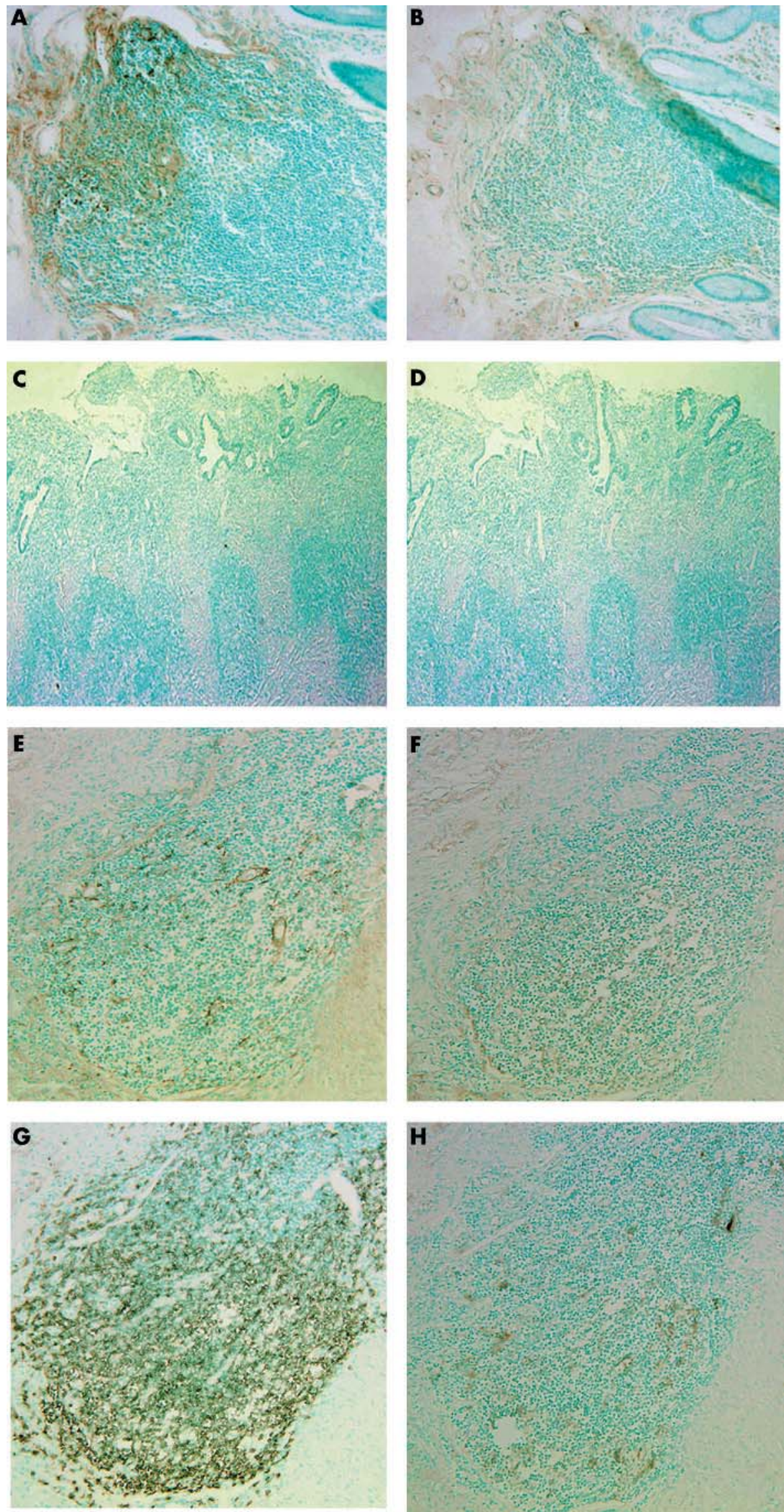
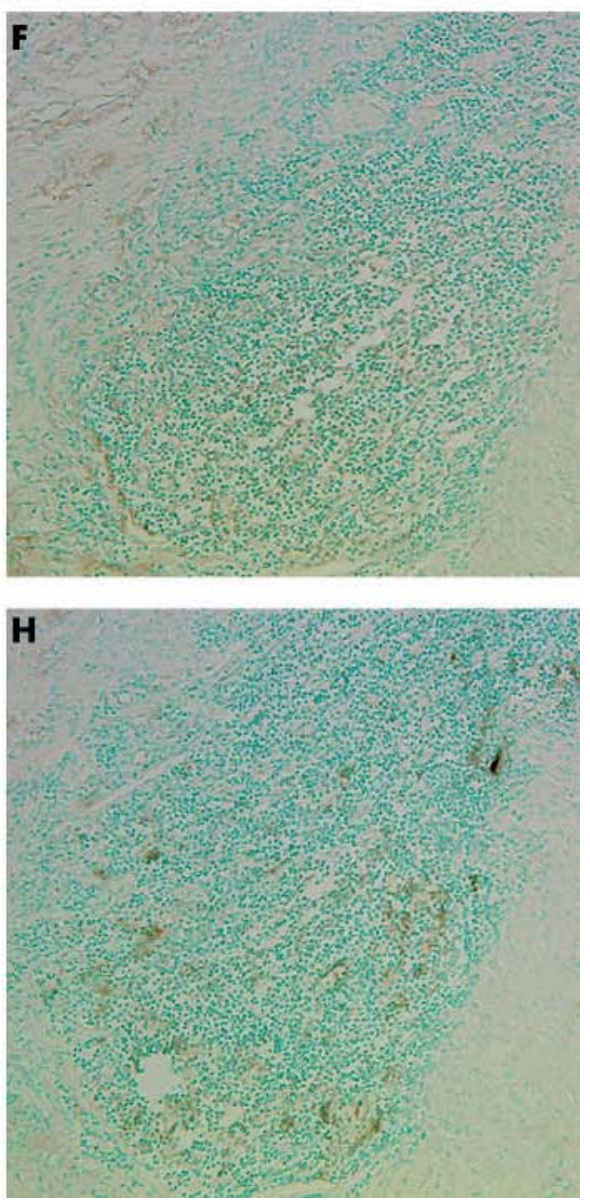

Figure 1 Expression of SLC

(secondary lymphoid tissue chemokine) and ELC (EBII ligand chemokine) in intestinal mucosa. Immunostaining for (A) SLC and (B) ELC in the controls. Immunostaining for (C) SLC and (D) ELC in ulcerative colitis (UC).

Immunostaining for (E) SLC, (F) ELC, (G)

CD3, and (H) CD83 in Crohn's disease (original magnification, $\times 100$ ). In the controls, a few venules and dendritic shaped cells in the follicle were stained for SLC, whereas ELC was almost negative. In specimens with UC, SLC and $E L C$ were almost negative in the intestinal mucosa. Many venules in the follicle were stained for SLC. ELC was sporadically stained in a few dendritic shaped cells. There were numerous CD3 and CD83 positive cells in the follicle. 
antirabbit IgG (Fab2) antibody (ICN Pharmaceuticals Inc, Aurora, Ohio, USA) at a $1 / 20$ dilution. Sections were mounted in glycerine gel and observed under a fluorescent microscope (Olympus BX50; Olympus, Tokyo, Japan) equipped with a colour camera (Olympus Colour Chilled 3CCD Camera; M-3204C).

\section{Real time quantitative reverse transcription polymerase chain reaction (RT-PCR)}

SLC, ELC, and CCR7 mRNA was quantified in the lymph nodes of nine patients with Crohn's disease and eight patients with UC using the primers and probes shown in table 3. Glyceraldehyde-3-phosphate dehydrogenase (GAPDH) was used as endogenous control (primers and probe from PE Biosystems, Foster City, California, USA).

RNA was isolated from lymph nodes using the SV total RNA isolation system (Promega, Tokyo, Japan). The reaction mixture was made by the addition of $12.5 \mu \mathrm{l}$ of $2 \times$ ThermoScript reaction mix, $0.5 \mu \mathrm{l}$ of ROX reference dye, $0.5 \mu \mathrm{l}$ of ThermoScript ${ }^{\mathrm{TM}}$ Plus/Platinum ${ }^{\circledR}$ Taq mix (Platinum Quantitative RT-PCR Thermo Script ${ }^{\mathrm{TM}}$ One-Step system; Invitrogen, Carlsbad, California, USA), $0.5 \mu \mathrm{l}$ of sense primer $(10 \mu \mathrm{M}), 0.5 \mu \mathrm{l}$ of antisense primer $(10 \mu \mathrm{M}), 0.5 \mu \mathrm{l}$ of probe $(10 \mu \mathrm{M}), 0.5 \mu \mathrm{l}$ of diethyl pirocarbonate treated water, and $5 \mu \mathrm{l}$ of total RNA sample. The RNA content was measured by light absorbance using Gene Quant Pro (Pharmacia Biotech, Cambridge, UK). Quantification of mRNA was performed using the ABI PRISM 7700 Sequence detection system (AB Applied Biosystems, Foster City, California, USA). ${ }^{19-21}$ After the initial step $\left(50^{\circ} \mathrm{C}\right.$ for 30 minutes and $95^{\circ} \mathrm{C}$ for five minutes), incubation at $95^{\circ} \mathrm{C}$ for 15 seconds and $60^{\circ} \mathrm{C}$ for one minute was repeated for 45 cycles. The fluorescence intensities of the PCR products were measured, and values were expressed as
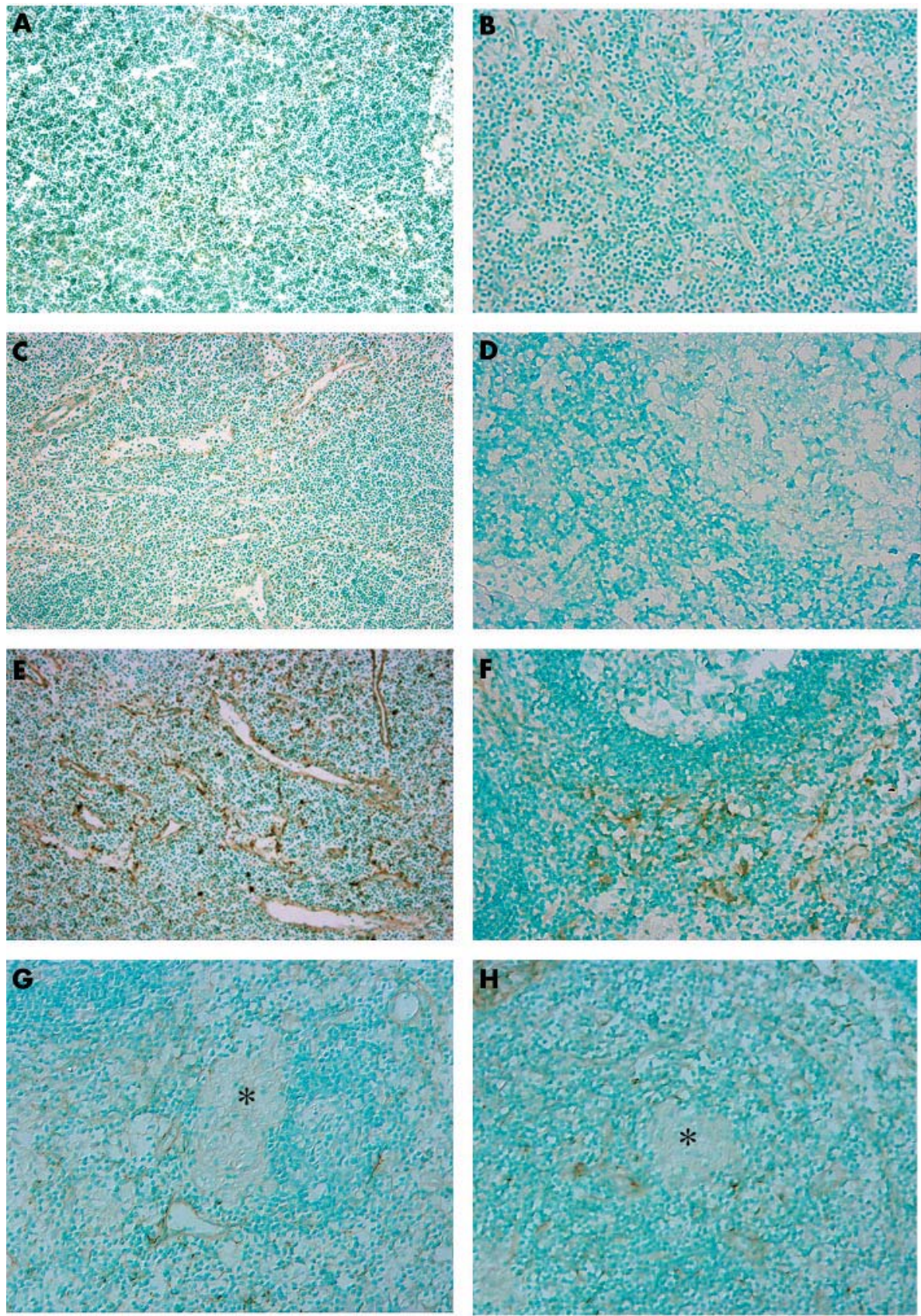

Figure 2 Expression of SLC (secondary lymphoid tissue chemokine) and $\mathrm{ELC}$ (EBII ligand chemokine) in lymph nodes. Immunostaining for (A) SLC and (B) ELC in normal controls. Immunostaining for (C) SLC and (D) ELC in ulcerative colitis (UC).

Immunostaining for (E) SLC and (F) ELC in Crohn's disease. Immunostaining for (G) SLC and (H) ELC in a Crohn's disease granuloma (original magnification, $\times 100$ ). In the controls, a few venules and dendritic shaped cells in the T cell zone were stained for SLC, whereas ELC was negative. In UC, both SLC and ELC were almost negative. In Crohn's disease, many venules and dendritic shaped cells in the T cell zone were stained for SLC and many dendritic shaped cells expressed ELC. No granuloma was stained for SLC and ELC in Crohn's disease. The asterisks indicate granulomas. 


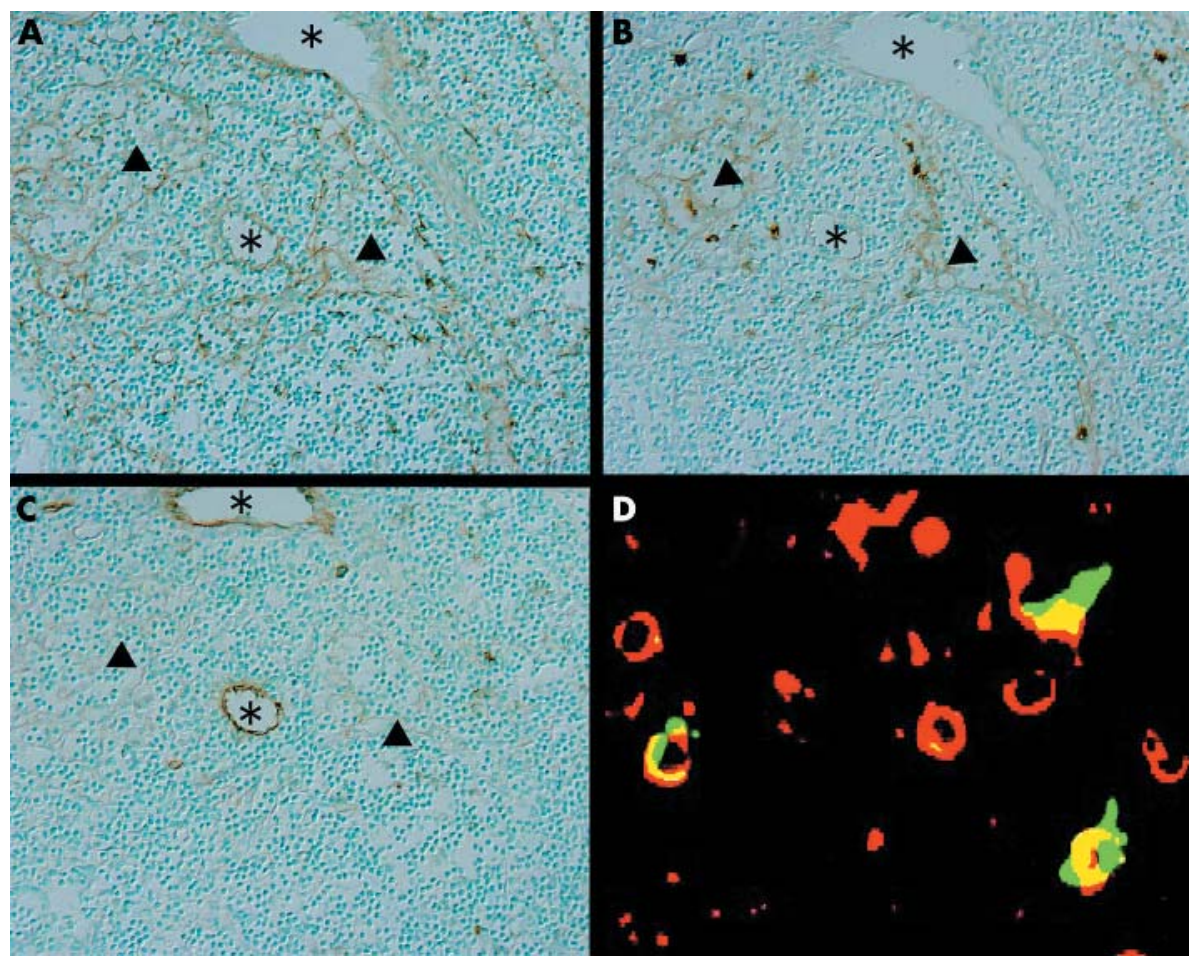

Figure 3 Serial sections

immunostained for (A) SLC (secondary lymphoid tissue chemokine), (B) VEGFR3, and (C) HECA452 showed that SLC positive venules correspond to VEGFR3 positive lymphatic vessels and to HECA452 positive high endothelial venules (HEVs). The asterisks indicate $\mathrm{HEV}$ s and the arrowheads indicate lymphatic vessels (original magnification, $\times 200)$. (D) Double immunofluorescence staining for CD83 (rhodamine, red) and ELC (EBI1 ligand chemokine; fluorescein isothiocyanate, green) in the T cell area. Cells that were positive for both CD83 and ELC are mature dendritic cells (original magnification, $\times 400$ ). logarithm of fluorescence against that of a standard sample.

\section{STATISTICAL ANALYSIS}

Results were analysed using the Mann-Whitney $U$ test. Differences were considered significant when $p$ values were less than 0.05 .

\section{RESULTS}

\section{Expression of SLC and ELC in human intestine}

Both SLC and ELC were expressed in lymphoid tissue such as lymph aggregates and lymph follicles in human intestine. SLC was rarely expressed in dendritic cells and in only a few vessels in lymph follicles of the control intestine (fig lA). ELC was not expressed in control intestine (fig $1 \mathrm{~B}$ ). In patients with UC, SLC and ELC were barely detectable in lymph aggregates of the inflamed colon (fig IC, D). In patients with Crohn's disease, SLC positive venules and dendritic cells were found in lymph aggregates (fig $1 \mathrm{E}$ ) and ELC was expressed in some dendritic cells (fig IF). CD3 positive T cells and CD83 positive dendritic cells were found in the lymph aggregates analysed by serial sections (fig IG, H). However, SLC and ELC were not expressed in granulomata of the Crohn's intestine.

Expression of SLC and ELC in mesenteric lymph nodes SLC was expressed in vessels and dendritic cells in the T cell zone (fig 2A) and ELC was occasionally expressed in the dendritic cells (fig 2B) of control mesenteric lymph nodes. Expression of SLC and ELC in patients with UC was similar to controls (fig 2C, D). Numbers of SLC positive vessels and dendritic cells and ELC positive dendritic cells were increased in the mesenteric lymph nodes of patients with Crohn's disease (fig 2E, F), whereas neither SLC nor ELC was detected in granulomas in Crohn's disease mesenteric lymph nodes.

\section{Identification of SLC positive vessels and ECL positive dendritic cells in mesenteric lymph nodes}

SLC positive vessels were identified using anti-HECA452 (vascular endothelial cell specific antibody) and anti-VEGFR3 (lymph vessel specific antibody) in serial sections. SLC was
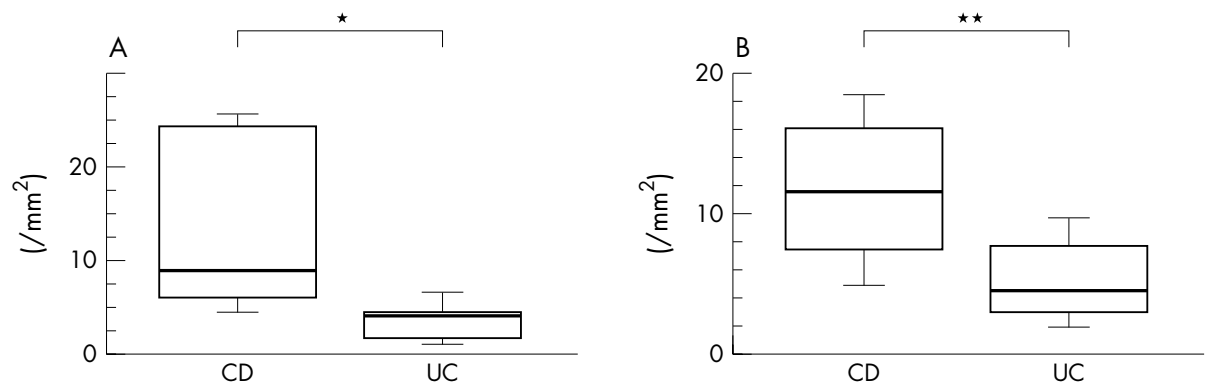

Figure 4 Numbers of (A) ELC (EBII ligand chemokine) positive mature dendritic cells and (B) SLC (secondary lymphoid tissue chemokine) positive high endothelial venules (HEVs) in the T cell area were compared between the mesenteric lymph nodes of 12 patients with Crohn's disease (CD) and 10 patients with ulcerative colitis (UC). There was a significant difference in ELC positive mature dendritic cells and SLC positive HEVs in lymphoid nodules between $C D$ and UC. The boxes show the median values with the 25 th and 75 th centiles. The bars show the 10th and the 90th centiles. ${ }^{*} p<0.05$; ${ }^{* *} \mathrm{p}<0.01$. 
present in HECA452 positive, VEGRF3 negative HEVs and HECA452 negative, VEGFR3 positive lymph vessels (fig 3A-C).

ELC positive dendritic cells located in the $\mathrm{T}$ cell zone of mesenteric lymph nodes that also express CD83 are mature dendritic cells (fig 3D).

\section{Quantification of SLC positive HEVs and ELC positive mature dendritic cells in mesenteric lymph nodes}

The numbers of SLC positive HEVs and ELC positive mature dendritic cells were significantly higher in patients with Crohn's disease than in those with UC (fig 4A, B).

\section{PCR quantification of SLC, ELC, and CCR7 mRNA}

SLC, ELC, and CCR7 mRNA was significantly higher in patients with Crohn's disease than in those with UC (fig 5).

\section{DISCUSSION}

An imbalance of the Thl/Th2 ratio contributes to various immunological disorders. The dramatic B cell response, ${ }^{19} 22$ comprehensive mRNA analysis of cytokines, ${ }^{21}$ and increased production of interleukin 5 (IL-5) by CD4 positive T cells in diseased intestine ${ }^{23}$ strongly suggest a role for the predominant Th2 response in the pathogenesis of UC. In contrast, increased numbers of interferon $\gamma$ producing $\mathrm{CD} 4$ positive $\mathrm{T}$ cells and IL-12 producing macrophages in inflamed intestine $^{710}$ have been reported in Crohn's disease, which is now widely recognised as a typical Thl dominant disorder. ${ }^{4}$ It is possible that activated $\mathrm{T}$ cells are recruited from the peripheral circulation to orchestrate the intestinal inflammation, although the primary mechanism for $\mathrm{T}$ cell recruitment remains unclear. Mesenteric lymph nodes and luminal lymphoid tissues are possible candidates for such recruitment.

Chemokines, which chemically attract leucocytes to inflammatory foci, are involved in particular immunoreactions. ${ }^{24-26}$ The expression of interferon inducible protein IC, IL-8, monocyte chemotactic proteins $1-3$, and macrophage inflammatory proteins $1 \alpha$ and $1 \beta$ in Crohn's disease and UC did not differ significantly, ${ }^{27-32}$ and the differential expression of chemokines in Crohn's disease and UC has not been reported previously. Although both SLC and ELC expressed in lymphoid tissue are known to be involved in the regulation of antigen specific T cells, ${ }^{1517} 18$ this is the first study to reveal

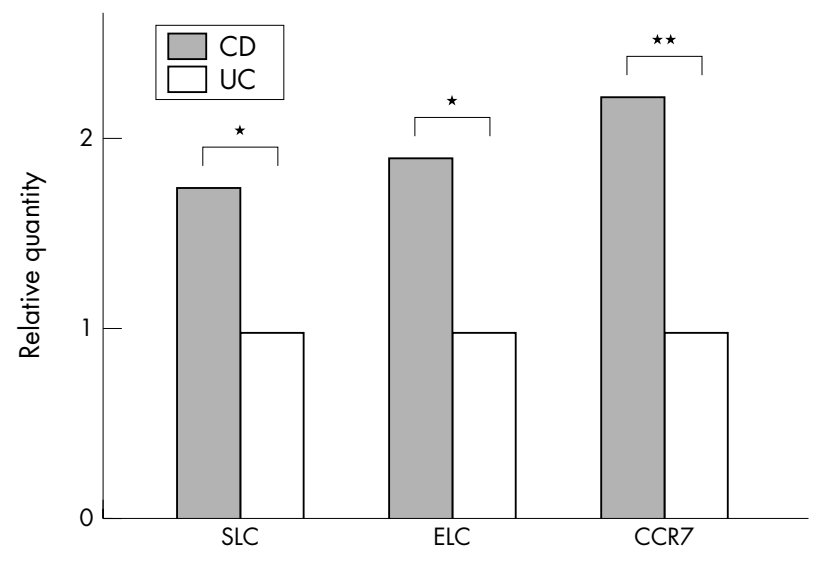

Figure 5 Real time quantitative polymerase chain reaction analysis of SLC (secondary lymphoid tissue chemokine), ELC (EBII ligand chemokine), and CCR7 mRNA expression in mesenteric lymph nodes from nine patients with Crohn's disease (CD) and eight patients with ulcerative colitis (UC). All values were normalised using glyceraldehyde3-phosphate dehydrogenase. There was a significant difference between $C D$ and UC for SLC, ELC, and CCR7 mRNA expression. " $p<0.05$; ${ }^{* *} p<0.01$. the expression of SLC and ELC in Crohn's disease gut associated lymphoid tissue (GALT).

We found that SLC and ELC were mainly expressed in the GALT T cell zone, which suggests that SLC and ELC function as $\mathrm{T}$ cell homing chemokines in the intestine. Expression of SLC and ELC was higher in the mesenteric lymph nodes than in the intestine, and in patients with Crohn's disease compared with controls and patients with UC.

We have reported previously that antigen presenting macrophages found in the intestinal granulomas of patients with Crohn's disease cause a Thl dominant immune response. ${ }^{510}$ In our present study, ELC was expressed in mature dendritic cells in Crohn's disease lymph nodes, whereas SLC and ELC were not expressed in macrophages located in granulomas of mesenteric lymph nodes or in the intestine of these patients. Katou and colleagues ${ }^{22}$ reported concomitant localisation of ELC positive mature dendritic cells and CD45RA naive T cells, and ELC negative mature dendritic cells and CD45RO memory $\mathrm{T}$ cells in chronic inflammatory human skin lesions. Therefore, a memory $\mathrm{T}$ cell immune response, rather than a naive $\mathrm{T}$ cell response is probably involved in granuloma formation in patients with Crohn's disease.

\section{"We found that SLC and ELC were mainly expressed in the gut associated lymphoid tissue T cell zone, which suggests that SLC and ELC function as T cell homing chemokines in the intestine"}

HEVs, lymphatic vessels, and mature dendritic cells are important in the regulation of the immune response of antigen specific $\mathrm{T}$ cells in lymph nodes. The number of SLC positive HEVs and lymphatic vessels, and ELC positive mature dendritic cells, was significantly higher in the mesenteric lymph nodes of patients with Crohn's disease than in patients with UC. Furthermore, real time quantification by RT-PCR revealed increased SLC, ELC, and CCR7 mRNA in the mesenteric lymph nodes of patients with Crohn's disease compared with those with UC. The expression of SLC and ELC, and their ligand CCR7, was higher in the mesenteric lymph nodes of patients with Crohn's disease than in those with UC in terms of both mRNA and protein. Such a discrepancy in chemokine expression between different inflammatory bowel diseases has not been reported previously. In Crohn's disease GALT, not only HEVs, but also lymphatic vessels, play an important role in the recruitment of memory $\mathrm{T}$ cells. Interestingly, the expression of these chemokines is more prominent in mesenteric lymph nodes than in the inflamed intestine. Mesenteric lymph nodes may

\section{Take home messages}

- Differential expression of SLC (secondary lymphoid tissue chemokine) ELC (EBII ligand chemokine), and their ligand, CCR7, in the mesenteric lymph nodes of patients with Crohn's disease suggests that abnormal antigen processing and $\mathrm{T}$ helper type 1 response skewing may be involved in the pathogenesis of Crohn's disease

- Mesenteric lymph nodes play an important role in T cell and dendritic cell recruitment in patients with this disease and may be the primary sites of T memory cell homing in this disease

- In the future, antibodies or drugs that suppress SLC and ELC may be useful in the treatment of Crohn's disease 
be the primary sites of $\mathrm{T}$ cell recruitment to the inflamed intestine and may perpetuate the inflammatory reaction by activating memory $\mathrm{T}$ cells in patients with Crohn's disease.

Dendritic cells in peripheral tissues begin maturation after phagocytosing antigens, followed by CCR6 downregulation and CCR7 upregulation, and are recruited to the lymph nodes by a reciprocal reaction with SLC, which is produced by lymphatic vessels. ${ }^{15}{ }^{17}$ In addition, CCR7 is expressed on naive $\mathrm{T}$ cells and Thl $\mathrm{T}$ cells. ${ }^{33}$ Increased expression of SLC in lymphatic vessels and HEVs triggers the recruitment of CCR7 positive dendritic cells and $\mathrm{T}$ cells, which leads to $\mathrm{T}$ cell zone hyperplasia in Crohn's disease lymph nodes. Dendritic cells recruited in lymph nodes produce CCR7 to interact with CCR7 positive T cells and expand the Thl immune response in Crohn's disease. Suppression of SLC and ELC in Crohn's disease GALT by antibodies or drugs is a possible future treatment for patients with Crohn's disease.

In conclusion, differential expression of SLC, ELC, and CCR7 in the mesenteric lymph nodes of patients with Crohn's disease characterises abnormal antigen processing and Thl skewing as a pathogenetic mechanism in Crohn's disease. Mesenteric lymph nodes play an important role in T cell and dendritic cell recruitment in patients with this disease.

\section{Authors' affiliations}

D Kawashima, N Oshitani, Y Jinno, K Watanabe, S Nakamura, K Higuchi, T Arakawa, Department of Gastroenterology, Osaka City University Graduate School of Medicine, 1-4-3, Asahi-machi, Abenoku, Osaka 545-8585, Japan

\section{REFERENCES}

1 Fiocchi C. Inflammatory bowel disease: etiology and pathogenesis. Gastroenterology 1998;115:182-205.

2 Shanahan F. Crohn's disease. Lancet 2002;359:62-9.

3 Ward M. The pathogenesis of Crohn's disease. Lancet 1977;29:903-5.

4 Neurath MF, Finotto S, Glimcher LH. The role of Th1/Th2 polarization in mucosal immunity. Nat Med 2002;8:567-73.

5 Kakazu T, Hara J, Matsumoto T, et al. Type 1 T-helper cell predominance in granulomas of Crohn's disease. Am J Gastroenterol 1999;94:2149-55.

6 Niessner M, Volk BA. Altered Th1/Th2 cytokine profiles in the intestinal mucosa of patients with inflammatory bowel disease as assessed by quantitative reversed transcribed polymerase chain reaction (RT-PCR). Clin Exp Immunol 1995;101:428-35.

7 Parronchi P, Romagnani P, Annunziato F, et al. Type 1 T-helper cell predominance and interleukin-12 expression in the gut of patients with Crohn's disease. Am J Pathol 1997; 150:823-32.

8 Monteleone G, Biancone L, Marasco R, et al. Interleukin 12 is expressed and actively released by Crohn's disease intestinal lamina propria mononuclear cells. Gastroenterology 1997;1 12:1169-78.

9 Plevy SE, Landers CJ, Prehn J, et al. A role for TNF-a and mucosal T helper-1 cytokines in the pathogenesis of Crohn's disease. J Immunol 1997; 159:6276-82

10 Hara J, Ohtani H, Matsumoto T, et al. Expression of costimulatory molecules B7-1 and B7-2 in macrophages and granulomas of Crohn's disease: demonstration of cell-to-cell contact with T lymphocytes. Lab Invest 1997;77:175-84.
11 Sallusto F, Mackay CR, Lanzavecchia A. Selective expression of the eotaxin receptor CCR3 by human T helper 2 cells. Science 1997;277:2005-7.

12 Loetscher $P$, Uguccioni $M$, Bordoli L, et al. CCR5 is characteristic of Th lymphocytes. Nature 1998;391:344-5.

13 Mackay CR. Follicular homing T helper (Th) cells and the Th1/Th2 paradigm. J Exp Med 2000;192:31-4.

14 Nagira M, Imai T, Hieshima K, et al. Molecular cloning of a novel human CC chemokine secondary lymphoid-tissue chemokine that is a potent chemoattractant for lymphocytes and mapped to chromosome 9p13. J Biol Chem 1997;272:19518-24.

15 Gunn MD, Tangemann K, Tam C, et al. A chemokine expressed in lymphoid high endothelial venules promotes the adhesion and chemotaxis of naive $\mathrm{T}$ lymphocytes. Proc Natl Acad Sci U S A 1998;95:258-63.

16 Yoshida R, Imai T, Hieshima K, et al. Molecular cloning of a novel human CC chemokine EBI1-ligand chemokine that is a specific functional ligand for EBII, CCR7. J Biol Chem 1997;272:13803-9.

17 Ngo VN, Tang HL, Cyster JG. Epstein-Barr virus-induced molecule 1 ligand chemokine is expressed by dendritic cells in lymphoid tissues and strongly attracts naive T cells and activated B cells. J Exp Med 1998;188:181-91.

18 Sallusto F, Palermo B, Lenig D, et al. Distinct patterns and kinetics of chemokine production regulate dendritic cell function. Eur J Immunol 1999:29:1617-25.

19 Gibson UE, Heid CA, Williams PM. A novel method for real time quantitative RT-PCR. Genome Res 1996;6:995-1001.

20 Heid CA, Stevens J, Livak KJ. Real time quantitative PCR. Genome Res 1996:6:986-93.

21 Sawa Y, Oshitani N, Adachi K, et al. Comprehensive analysis of intestinal cytokine messenger RNA profile by real-time quantitative polymerase chain reaction in patients with inflammatory bowel disease. Int $\mathrm{J}$ Mol Med 2003;11:175-9.

22 Katou F, Ohtani H, Nakayama T. Differential expression of CCL19 by DCLamp+ mature dendritic cells in human lymph node versus chronically inflamed skin. J Pathol 2003;199:98-106

23 Fuss IJ, Neurath $M$, Boirivant $M$, et al. Disparate CD4+ lamina propria (LP) lymphokine secretion profiles in inflammatory bowel disease. Crohn's disease LP cells manifest increased secretion of IFN-gamma, whereas ulcerative colitis LP cells manifest increased secretion of IL-5. J Immunol 1996;157:1261-70.

24 Qin S, Rottman JB, Myers P, et al. The chemokine receptors CXCR3 and CCR5 mark subsets of $\mathrm{T}$ cells associated with certain inflammatory reactions. J Clin Invest 1998;101:746-54.

25 Kawasaki S, Takizawa H, Yoneyama H, et al. Intervention of thymus and activation-regulated chemokine attenuates the development of allergic airway inflammation and hyperresponsiveness in mice. $J$ Immunol 2001; 166:2055-62.

26 Panina-Bordignon P, Papi A, Mariani $M$, et al. The $C-C$ chemokine receptors CCR4 and CCR8 identify airway T cells of allergen-challenged atopic asthmatics. J Clin Invest 2001;107:1357-64.

27 Izzo RS, Witkon K, Chen Al, et al. Interleukin-8 and neutrophil markers in colonic mucosa from patients with ulcerative colitis. Am J Gastroenterol 1992;87:1447-52

28 Izzo RS, Witkon K, Chen Al, et al. Neutrophil-activating peptide (interleukin-8) in colonic mucosa from patients with Crohn's disease. Scand J Gastroenterol 1993;28:296-300.

29 Uguccioni M, Gionchetti P, Robbiani DF, et al. Increased expression of IP-10, IL-8, MCP-1, and MCP-3 in ulcerative colitis. Am J Pathol 1999;155:331-6.

30 MacDermott RP, Sanderson IR, Reinecker HC. The central role of chemokines (chemotactic cytokines) in the immunopathogenesis of ulcerative colitis and Crohn's disease. Inflamm Bowel Dis 1998;4:54-67.

31 Mazzucchelli L, Hauser C, Zgraggen K, et al. Differential in situ expression of the genes encoding the chemokines MCP-1 and RANTES in human inflammatory bowel disease. J Pathol 1996;178:201-6.

32 Banks C, Bateman A, Payne R, et al. Chemokine expression in IBD. Mucosal chemokine expression is unselectively increased in both ulcerative colitis and Crohn's disease. J Pathol 2003;199:28-35.

33 Randolph DA, Huang G, Carruthers CJL. The role of CCR7 in Th1 and Th2 cell localization and delivery of B cell help in vivo. Science 1999;286:2159-62. 